\title{
Rodolfo Garcia esboçado em cartas: tensões entre o erudito e o intelectual ${ }^{*}$
}

\author{
Rodolfo Garcia outlined in letters: Tensions between the erudite and \\ intellectual
}

\author{
Gabriela D'Avila Brönstrup \\ gabidbronstrup@gmail.com \\ Mestre \\ Universidade Estadual Paulista \\ Rua Oratório, 1578, apto 06, Parque das Nações \\ 09280-000 - Santo André - São Paulo \\ Brasil
}

\begin{abstract}
Resumo
As demandas que um indivíduo recebe no exercício de seu ofício por meio de correspondências possibilitam a análise dos papéis atribuídos e da construção de sua imagem. Neste artigo, trataremos de algumas das consultas feitas a Rodolfo Augusto de Amorim Garcia (1873-1949), um autodidata que produz história durante as décadas de 1930 e 1940, por meio de correspondências enviadas pelos pares. As variações na forma com que os remetentes identificaram Garcia, ora como erudito, ora como intelectual, provocaram algumas inquietações: que atividades os chamados eruditos desenvolviam? Quais as motivações daqueles que se dirigiram a Rodolfo Garcia como intelectual? Que contribuições daria ele ao trabalho de integrantes da chamada tradição ensaística, emergente no Brasil durante a primeira metade do século XX? Tais reflexões servirão como fio condutor na 11 investigação dos usos dos saberes em um período de investimentos na formação de profissionais e delineamento de um novo modelo de historiador no Brasil.
\end{abstract}

\section{Palavras-chave}

Historiador; Erudição; Intelectual.

\begin{abstract}
The demands a person handles on letters over his crafts enable the analysis of the roles this person assumes and the building of his personal image. This paper deals with some queries that were asked to Rodolfo Augusto de Amorim Garcia (1873-1949), an autodidact who produced history during 1930s and 1940s through letters to his pairs. The different manners Garcia is identified - sometimes erudite, sometimes intellectual - raised some questions: What were the activities the so-called erudites carried out? What reasons led some of them to call Garcia an intellectual? What contribution could be assigned to him on the so-called essayistic tradition that emerged in Brazil during the first half of the 20th century? Such reflections will guide the research on the use of knowledge in a period of investments on professional training and of shaping a new model of historians in Brazil.
\end{abstract}

Keywords

Historian, Erudition, Intellectual.

Recebido em: 21/10/2016

Aprovado em: 31/8/2017

\footnotetext{
* A pesquisa contou com financiamento do Programa Nacional de Apoio à Pesquisa (PNAP)/Biblioteca Nacional e da Fundação de Amparo à Pesquisa do Estado de São Paulo (Fapesp).
} 
Os primeiros esforços que resultaram na constituição dos cursos universitários de História no Brasil na década de 1930 possibilitaram uma importante mudança na produção dessa área. No entanto, as novas formas de se relacionar com o conhecimento histórico e seus produtores se configuraram lentamente e contaram com a participação de muitos dos chamados homens de letras. Tais letrados eram autodidatas no conhecimento histórico e necessitavam de determinados requisitos para tornarem-se reconhecidos como historiadores. A maneira de conceber a identidade e nomear os que se dedicavam aos estudos históricos no Brasil também ganhou novas possibilidades durante a primeira metade do século XX. Assim, as mudanças nas regras desse saber com pretensões de cientificidade abriram caminho para a coexistência da figura antiga do erudito com a do intelectual.

Neste artigo, trataremos de algumas das "encomendas" feitas a Rodolfo Garcia por meio de cartas enviadas por seus pares, amigos e autoridades estatais durante as décadas de 1930 e 1940. Essas narrativas, integrantes de projetos de construção identitária da figura de Rodolfo Garcia, são repletas de relações de alteridade, as quais perpassam o lugar social, as práticas do ofício e seu produto que é o texto histórico (CERTEAU 1982). Considerando as correspondências como representantes desse lugar social de fala, o qual confere posições aos que dele participam, tais fontes abrem caminhos para a análise das incumbências destinadas a Garcia nos contextos institucionais e disciplinares específicos, bem como para o estabelecimento dos critérios utilizados por seus pares, em relação ao que é ser erudito, intelectual e historiador. Para adentrar nesses critérios, buscamos investigar as hierarquias de virtudes atribuídas a Garcia no que se refere à produção do conhecimento histórico, atentos também às demandas recebidas, pois possibilitaram que priorizasse determinadas virtudes em detrimento de outras. Nesse sentido, aliás, Herman Paul (2016, p. 31) sugere: "Não se pode especificar o quanto se aperfeiçoou o conhecimento histórico sem prestar atenção às demandas de uma situação historiográfica específica".

Rodolfo Augusto de Amorim Garcia, historiador autodidata, graduou-se em direito em Recife, onde trabalhou como jornalista, professor de história, geografia, francês e português nos Colégios Wolf e Santa Margarida. Mais tarde, mudou-se para o Rio de Janeiro, atuando inicialmente como bibliotecário no Instituto Histórico e Geográfico Brasileiro. Nas décadas de 1930 e 1940, esteve inserido nos principais locais de produção do conhecimento histórico: foi membro da Academia Brasileira de Letras, sócio benemérito do IHGB e diretor do Museu Histórico Nacional de 1930 até 1932, ano em que iniciou o primeiro Curso de Museus do Brasil e passou a ocupar o cargo de diretor na Biblioteca Nacional, trabalhando na reabertura do curso de Biblioteconomia. Dentre as "encomendas" que recebeu por correspondência estão a anotação de textos históricos e a participação em inquéritos com temas relacionados aos projetos na área da cultura. Por meio da análise desse material, investigaremos alguns dos papéis atribuídos a ele e a seus pares nesse período no qual se delineava um novo modelo de historiador no Brasil. 


\section{Rodolfo Garcia entre os "intellectuaes mais autorizados"}

Comecemos pelas encomendas feitas por Gustavo Capanema. Eram geralmente datilografadas em papel timbrado do Ministério da Educação e Saúde, instituição de que esteve à frente desde 1934 até 1945 - quase os mesmos longos anos em que Rodolfo Garcia ocupou também um cargo público, subordinado ao mesmo Ministério, enquanto diretor da Biblioteca Nacional, entre 1932 e 1945. A permanência de Garcia naqueles anos de incerteza nos quais o golpe do Estado Novo foi planejado e executado parece justificar-se tanto pelo conjunto de saberes de "cultura geral", e especialmente da história do Brasil, que possuía e dispunha para a edificação da nação quanto pelas boas relações que procurou manter com os representantes do poder político.

Por essa época, ocorrem modificações na forma de recrutar os chamados intelectuais para os cargos públicos. A dependência das relações familiares e pessoais que dava acesso a esses postos na Primeira República começa a ser substituída por outros critérios, como a exigência do diploma universitário, acompanhada de determinada especialização na área de atuação. No entanto, tal processo se configura lentamente, e mesmo com a burocratização dos aparatos estatais as formas tradicionais de contratações e alterações no quadro de funcionários não deixam de coexistir. Nessa jornada dupla de trabalho, muitos contavam com a viabilização do próprio Estado, que promovia a difusão das obras que Ihes interessavam. Garcia integrou o grupo de funcionários-historiadores e, por meio das letras, garantiu seu posto no projeto cultural ambíguo que

116 Gustavo Capanema dirigiu, o qual combinou a criação de um mecenato estatal para a valorização dos chamados eruditos a investimentos na substituição dos formalismos da República pela produção de símbolos culturais do Estado Novo (SCHWARTZMAN; BOMENY; COSTA 2001).

Ao cercar-se de nomes ligados a diversas áreas e perspectivas do conhecimento que reconheceu como intelectuais, Capanema concedeu-lhes cargos ou enviou inquéritos, uma de suas práticas recorrentes para obter pareceres a respeito de assuntos que considerava relevantes. Em novembro de 1936, enviou para Rodolfo Garcia uma circular de interesse da Comissão de Teatro Nacional, que fora criada naquele mesmo ano, indicando o início de um processo de constituição de uma política governamental para o teatro. Dentre as principais atribuições da Comissão estava a promoção de estudos a respeito da história da literatura dramática estrangeira e a seleção de obras para a tradução, que ficou a cargo de Sérgio Buarque de Hollanda. A circular enviada a Rodolfo Garcia solicitava a indicação de vinte peças que correspondessem aos seguintes critérios: a) serem obras-primas da literatura; b) terem sentido universal e harmonioso; c) serem capazes de despertar interesse no grande público. Mas, antes de apresentar esse inquérito, redigido por Sérgio Buarque, havia uma identificação do grupo a quem se destinava: "Para a escolha dessas obras opina a Comissão de Theatro Nacional que nenhum processo será mais adequado e seguro do que organizar-se um inquérito entre nossos intellectuaes mais autorizados para falar sobre o assumpto". 
Se os destinatários eram os "intellectuaes mais autorizados" para tratar de "teatro universal", que virtude incluiria Rodolfo Garcia nesse rol? Suas pesquisas, dedicadas principalmente à publicação comentada de documentos e anotação de obras de história do Brasil Colônia, pouco ou nada trataram de teatro. A dificuldade na demarcação de fronteiras entre as áreas do conhecimento que participavam de um projeto de constituição da "cultura brasileira" no período e a insipiência do teatro enquanto área do conhecimento no Brasil são algumas possibilidades, que, no entanto, valeriam para a escolha de qualquer outro. $O$ acesso privilegiado à literatura dramática estrangeira enquanto diretor da BN foi, provavelmente, critério definidor na inclusão de Garcia entre os capacitados para tratar do teatro universal, mas também esse cargo devia-se ao reconhecimento que adquirira como historiador erudito.

Seja como for, nessa condição, Garcia ganhou autoridade para também definir quem era erudito. Afonso de Escragnolle Taunay é um dos que escreve para Garcia com intuito de sanar uma dúvida nesse sentido. Da mesma forma que Garcia, Taunay integrou um grupo de letrados dedicados à busca documental e à escrita metódica conforme a concepção moderna de história, orientada por Capistrano de Abreu na historiografia brasileira. Guiado pelo principio da busca da verdade, Taunay indaga acerca da procedência de um autor: "O que o senhor sabe a respeito de Frei João de Arronches? Seria realmente um erudito?" (TAUNAY 23 abr. 1926) A pergunta de Taunay, vinda por carta, sinaliza que considerar um autor como erudito implicava em atestar virtudes que conferiam credibilidade ao resultado de seu trabalho. Tal questionamento nos provoca dúvidas mais amplas: De que maneira se tornava um erudito no Brasil naquele período? Que atividades os chamados eruditos desenvolviam?

\section{Conhecedores das "provas" do passado}

"Erudito" foi um dos termos utilizados entre os homens de letras brasileiros nas primeiras décadas do século XX para referir-se a um sujeito dotado de vastas informações, que, de modo geral, circulava por diversas áreas do conhecimento, em seus principais locais de produção e possuía formação autodidata ou em área diferente daquela a que se dedicava: as humanidades. Pode-se considerar ainda o domínio da linguagem literária e o interesse pelo estudo da Antiguidade, ou do que se relacionasse ao "antigo", como uma de suas marcas. Tal atenção ao antigo é associada também à figura do antiquário. Esse "perfil" do erudito anterior ao século XIX, que se dedicava à Antiguidade Greco-romana, foi constituído de autoridade no estudo do passado por venerar peças originais, como cartas, selos, brasões, e voltar-se ao estudo de instituições políticas, costumes, religiões, invenções e línguas caídas em desuso, por exemplo. Para lidar com esses materiais e informações, os antiquários desenvolveram métodos críticos de pesquisa visando a obter um conhecimento sistemático, situar essas peças cronologicamente e praticar a exegese documental, acumulando, deste modo, um vasto saber pautado em detalhes (MOMIGLIANO 2004; GRAFTON s.d., p. 109-135).

É possível, portanto, relacionarmos a prática de pesquisa dos antiquários à conformação do método de crítica documental que fundamenta a historiografia 
moderna, especialmente no que se refere às fontes como via de comprovação de um passado, talvez não tão longínquo para o antiquário como para o historiador moderno. Mas, qual a percepção dos que concebiam o conhecimento histórico a partir de suas variedades modernas, instauradas desde fins do século XVIII, a respeito da maneira que os antiquários lidavam com o passado? Os antiquários pareciam ter uma experiência específica com o passado, pois os materiais investigados por eles não significavam apenas meios de chegar à verdade dos fatos pretéritos: eles continham uma espécie de passado perpetuado, estabelecendo assim uma forte relação de continuidade com o presente. Já no regime historiográfico moderno, a história é entendida como processo no qual o tempo se move para um fim, o que faz com que o futuro ganhe mais espaço no presente que o passado. Nesse sentido, Arnaldo Momigliano aponta que o antiquário era visto pelos modernos como "aquele que se interessa pelo passado sem se interessar pela história" (MOMIGLIANO 2004, p. 85).

Para além de certo desdém, essa nova experiência de tempo, em que passado e presente são articulados em função do futuro, rendeu um novo estatuto à tradição e às práticas eruditas. A importância que foi atribuída por países europeus ao conhecimento do passado em busca de avaliar o presente e projetar o futuro visando ao progresso, impulsionou um novo interesse pelas "antiguidades nacionais" no campo da história; promoveu, também, a incorporação de técnicas eruditas como a exegese documental, bem como uma aproximação às chamadas ciências auxiliares, dentre elas a filologia, a arqueologia

118 e a cronologia, fazendo com que alguns dos saberes dos chamados antiquários fossem utilizados na produção do conhecimento histórico (GUIMARÃES 2000).

Diversos usos do passado na formulação de projetos com vistas ao futuro e à conformação de uma identidade nacional também foram constantes na historiografia brasileira e aumentaram a busca de fontes desde o século XIX. Mesmo que não tenha sido nomeado antiquário e que suas aspirações em relação aos vestígios do passado tenham lhe dado o status de historiador, Rodolfo Garcia figurou entre os conhecedores de um suporte de "antiguidade nacional" privilegiado pelos que se dedicavam à escrita da história do Brasil: o documento escrito. No entanto, seu interesse pelos vestígios do passado centralizado nos suportes textuais não se reduziu a eles. Em algumas das incumbências recebidas por correspondência, percebe-se que a experiência obtida enquanto diretor da Biblioteca Nacional é que o tornou habilitado por seus contemporâneos a desenvolver algumas atividades próximas do chamado antiquário. Vejamos esse pedido de Antonio da Silva Ferreira Costa:

Possuo varios livros com data bastante antiga e de vários autores, e entre eles existe um que aqui não apareceu quem podesse decifrar o ano da edicão. E são como segue: Primeiro: Um dicionário encyclopedico, (2 volumes), por D. Jose Maria de Almeida Correa de Lacerda, Quinta edicão, ano 1878. Segundo: A Biblia Sagrada, "O Velho e Novo Testamento", tradução do Padre Antonio Pereira de Figueiredo, ano 1852. Terceiro: Biblia (em latim) ano de -M.D> LXIII. Quarto: Arte poética de Q. Horacio Placo. Escrita em latim e português por Candido Luzitano, ano D.CC.LVIII. Quinto: Intitucione de Verborum significatione et Regulis Juris [...]. Junto 
Remeto fotografias para milhor avaliar. Éra todo meu desejo que V. Exa me elucidasse do valor desses livros inclusive o material de cada um. Tambem possuo um bronze estilo Romano do qual junto também uma fotografia, assim como de Cristo, tambem em bronze conforme fotografia e obra de Teixeira Lopes, portuguêz. Para esses também pedia a V. Exa bondade de vossas referencias (COSTA 6 abr. 1945).

Além de avaliar obras, Costa confiou também a Garcia a análise de materiais iconográficos, ampliando a aposta em seu conhecimento de tipologias textuais para outros suportes. Sem uma política nacional orientadora na qualificação de acervos, os critérios de raridade que agregam valor simbólico e monetário às obras também variavam em cada instituição naquele tempo; a Biblioteca Nacional, no entanto, tornara-se referência nesse sentido desde o século XIX. Na atribuição de valor às obras, diversos elementos eram tomados como parâmetro, dentre eles a autoria, o período da impressão, existência de comentários ou dedicatória do autor, qualidade do papel, da encadernação e tipo de edição: especiais, clandestinas, censuradas, esgotadas ou com tiragem reduzida, etc. Mesmo partindo de alguns parâmetros, essa atividade requeria uma virtude importante também para o antiquário: a experiência, obtida pela prática de adquirir materiais nos quais se identificava "valor" cultural e histórico. Por um lado, essas "consultorias" exigiam de Garcia esforços análogos àqueles realizados na ampliação dos acervos da $\mathrm{BN}$ e do $\mathrm{MHN}$, em que também ocupou o cargo de diretor no ano de 1932; por outro, avaliar materiais que compunham um acervo iconográfico e bibliográfico em diálogo com a museologia e biblioteconomia, saberes de cuja institucionalização também participa durante a década de 1930, ${ }^{1}$ eram atividades diferentes de emitir parecer a respeito de materiais isolados, pois o valor de um acervo era estimado pela configuração do todo que os materiais compunham. Essa visão de conjunto não foi exercida por Rodolfo Garcia apenas no que se refere ao acervo da BN e do MHN:

Meu Prezado Rodolpho Garcia: Há tempos dirigi-Ihe dois cartões de visita numerados, no mesmo envelope, solicitando a sua opinião sobre a classificação, em importância, de algumas brasilianas, públicas e particulares, que existiram e ainda existem no Brasil. Tendo examinado algumas delas mais de perto do que eu, encontra-se você nas condições de me fornecer tal subsídio, ou informação autorizada, para firmar meu conceito, em ligeiro estudo comparativo, produzido por mim. PerguntavaIhe eu, mais ou menos, qual a ordem de valor ou supremacia, que deveriam ser colocadas as seguintes coleções: 1) a da Biblioteca Nacional, havida pela primeira do Brasil e do Mundo; 2) a do Instituto Histórico Brasileiro; 3) o antigo acervo, monograficamente catalogado pelo Dr. José Carlos Rodrigues e hoje incorporado à Biblioteca Nacional; 4) a reunião dos livros dos assumptos, contidos no Itamaraty; 5) a Biblioteca que pertenceu a Alberto Lamego, a que foi vendida, á municipalidade de São Paulo, pela viúva Felix Pacheco (GÓES 4 nov. 1937).

\footnotetext{
${ }^{1}$ Enquanto diretor do Museu Histórico Nacional e da Biblioteca Nacional, Rodolfo Garcia encaminhou as propostas de criação do Curso de Museus e da reativação do Curso de Biblioteconomia. Além disso, ministrou a disciplina História Política e Administrativa do Brasil (período colonial), parte da grade curricular do Curso de Museus. A configuração desses saberes especializados para o trabalho com acervos buscou tornar científicas suas práticas e partilhar da missão de desenvolver a cultura nacional pela via da ilustração.
} 
Rodolfo Garcia provavelmente atribuiu ao acervo da instituição que dirigia a primeira colocação na resposta dada a Eurico de Góes, diretor da Biblioteca Municipal de São Paulo por muitos anos. Mas, o que interessa percebermos, para além do parecer de Garcia que não encontramos, é o valor simbólico atribuído às "brasilianas" e sua relação com o conhecimento histórico.

Em meio à ânsia pelo "moderno", que acelerou as transformações presenciadas pelos letrados desde o início do século XX nos modos de vida, no espaço público ou mesmo nas profissões, as coleções abrigadas em prédios como o da BN e o Palácio do Itamaraty pareciam estar em direção oposta à novidade. No entanto, essas "antiguidades" a que tais materiais e espaços remetiam não eram entulhos, mas preciosidades. Tinham função fundamental na construção de um Brasil "civilizado", que deveria compartilhar da valorização às letras, aos moldes dos países europeus. Além disso, sem as "provas" do passado, por meio das quais era possível escrever a história, o futuro não teria seu devido destaque na constituição dessa nação promissora.

A figura de Rodolfo Garcia tornou-se, de tal forma, referência para todo tipo de conhecimento dessas "provas" do passado, desde a orientação a respeito do paradeiro de um documento e sua credibilidade até a indicação de profissionais para restaurar manuscritos. Afinal, o diretor da BN, incumbido de garantir a conservação de um grande acervo, era um dos poucos que saberia indicar um bom zincógrafo:

Meu eminente coetâneo: Mais uma vez lhe bato ao ferrolho com afetuoso importuno. Recorro a sua bondosa assistência para haver um informe que ninguém me sabe fornecer. Preciso de zincografar um manuscrito, mas este se acha com as letras mui apagadas. Indica-me artista capaz de fazer o restauro, com absoluto respeito ao que consta em tal documento? (VARELA 28 fev 1942).

Nessa carta enviada por Alfredo Varela, um dos fundadores do Instituto Histórico e Geográfico Rio-grandense, nota-se que, além da restauração do manuscrito, há uma preocupação com a fidelidade ao documento original. Como é sabido, esse aspecto foi fundamental não só para Varela como para Garcia e todos os que compartilhavam de uma concepção moderna da história, na qual o documento deveria ser submetido a procedimentos críticos que comprovassem sua autenticidade. Assim, trabalhar para e na conservação dos documentos era também colaborar para a escrita da história do Brasil em bases sólidas e confiáveis. Tanto na carta de Costa quanto na de Varela, Rodolfo Garcia é solicitado como conhecedor das "provas do passado": se Costa reclama que não encontrou alguém que pudesse "decifrar" o ano de edição de uma das suas obras, Varela também aponta que ninguém soubera fornecer a informação de que precisava. Dentre os letrados dedicados aos estudos históricos, aqueles que se dedicavam a um trabalho mais técnico com os documentos, mapeando coleções documentais e estudando os sistemas de classificação, restauração e conservação desses materiais, compunham um grupo seleto. Essas práticas, com raízes inclusive no saber antiquário, também ganharam novas formulações 
com os cursos de Biblioteconomia e de Museus, que incluíram os saberes antigos entre as novidades profissionais daquele período de transições.

Como vimos, apenas a descrição de possíveis características do chamado erudito não nos guiará, no caso brasileiro, até essa figura que é multifacetada. A análise das atividades de sujeitos considerados como tal, contudo, pode apontar para alguns desdobramentos do que a palavra significou naquele período, ou mesmo para a utilização simultânea dos termos "erudito" e "intelectual" para designar um mesmo perfil. Diante de inquietações tão amplas, retorno para a "caixa de correio" de Rodolfo Garcia, vasculhando as encomendas enviadas por Capanema e as motivações dos que se dirigiram a Garcia como erudito ou intelectual.

Dessa vez, encontramos uma oferta de $\operatorname{Cr} \$ 10.000,00$ como pagamento de uma encomenda já entregue. Trata-se da reedição anotada da História da República Jesuítica do Paraguai, de autoria do cônego João Pedro Gay, feita a pedido de Capanema. Alfredo Varela, quando soube que Garcia iniciaria esse trabalho, em 1941 Ihe escreveu: "Folgo com a notícia de que vai anotar o Gay. Faço idéia das eruditas, suculentas notas que nos promete." (VARELA 8 out. 1941). Varela associa a figura de Garcia à erudição pelo elogio às anotações, expressando como sua maneira de produzir o conhecimento histórico legitimou sua figura e a de muitos dos chamados homens de letras como eruditos. As anotações, de fato, foram uma prática constante na produção de Rodolfo Garcia, ao lado da divulgação documental e de uma escrita pautada nos procedimentos metódicos, de acordo com a concepção moderna de história orientada, especialmente, por Capistrano de Abreu, com quem anotou obras como a História Geral do Brasil, de Varnhagen, e História do Brasil, de Frei Vicente do Salvador. Desta última publicação, revisada em 1918, coube a Capistrano escrever a nota preliminar na qual agradece aos colaboradores, dentre eles Garcia, por prestar os melhores serviços na "correcção das provas". A resposta de Garcia chegou por carta:

Meu caro Dr. Capistrano, amigo e mestre,

Acaba de chegar-me às mãos sua carta de $1^{0}$ deste, pela qual the sou muito obrigado. Recebi há dias o exemplar da História de Fr. Vicente do Salvador que me destinou. Como Ihe agradecer a oferta e mais ainda a menção de meu apagado nome no prólogo desse livro imortal, não sei francamente: creia apenas que considero aquela página o melhor diploma de minha carreira literária (GARCIA s. d.).

Garcia demonstra a satisfação de ter uma meta de sua carreira literária alcançada: participar da revisão de uma obra estimada e receber o reconhecimento do mestre pelo trabalho. A autoridade para identificar "falsas provas" do passado e corrigi-las com "provas legítimas" tinha o aval do mestre e seria reafirmada pelos pares nas décadas seguintes.

Nesse sentido, muitos dos chamados eruditos do final do século XIX e das primeiras décadas do século XX partilharam de uma nova erudição histórica. Esta fazia com que se diferenciassem dos antecessores pela busca de uma história científica em que não bastava acumular os vestígios do passado, mas sim submetê- 
los a procedimentos rigorosos de verificação documental, priorizando as virtudes da fidelidade, objetividade e neutralidade na classificação desses materiais.

Os mesmos tipos de atividades e virtudes que fundamentaram a constituição da imagem de Rodolfo Garcia enquanto erudito foram também motivações para Capanema se referir a ele como intelectual. Nesse caso, a elaboração de notas em obras de história com "absoluta fidelidade" ao original:

De como o ilustre historiador realizou esse trabalho, dí-lo a bela publicação hoje distribuída, em que o original do cônego Gay nos é apresentado com a absoluta fidelidade à edição de 1863, enriquecida por 514 anotações de pé de página e 39 notas complementares. A proficiência do organizador e o esmero posto na tarefa justificam os melhores louvores ao douto intelectual, a quem já os transmiti, em nome de V. Exc. (CAPANEMA 7 jun. 1943).

Para investir em iniciativas de profissionalização e especialização, o ministro envolveu sujeitos que lidavam de diferentes formas com 0 conhecimento histórico: tanto aqueles que possuíam o saber abrangente e autodidata e produziam grandes sínteses, ou possuíam um conhecimento que se fundamentava pelos dados documentais relativos à história do Brasil, como também com os considerados intérpretes do Brasil, como Sérgio Buarque de Holanda, Gilberto Freyre e Caio Prado Junior, mais próximos à figura do intelectual. Portanto, o termo intelectual se tornou usual no Estado Novo, configurando-se como uma noção abrangente que deu uma roupagem nova aos que representavam a ilustração. Assim, uma só designação abarcou formas diversas de atuação e compreensão dos saberes representados.

Em meio a essas tensões entre a figura do erudito e do intelectual que se adensaram na década de 1930, Garcia parece adequar-se mais ao perfil do erudito, seja por conhecer minuciosamente um grande número de fontes documentais, dedicando-se ao seu tratamento e divulgação, seja por desempenhar a função de funcionário público e ter os estudos históricos como ofício paralelo, mesmo que as atividades estivessem associadas, ou ainda pela "cara fechada" e conhecimento amplo. No entanto, tais características não o impediram de estabelecer uma troca de saberes com os chamados intelectuais - aliás, seu conhecimento factual foi uma das maiores motivações para que nomes como Gilberto Freyre, Caio Prado Junior e Sergio Buarque de Holanda "cruzassem" com ele por correspondência. Esses integrantes da chamada tradição ensaística, emergente no Brasil durante a primeira metade do século $\mathrm{XX}$, descentralizaram os aspectos cronológicos e os vários "detalhes" eruditos que constituíam a maioria dos estudos monográficos para cunhar, cada um com suas especificidades, interpretações do processo histórico nacional a partir de novas maneiras de entender o país e outro estilo de escrita da história.

Mas, que contribuições daria Rodolfo Garcia ao trabalho daqueles a quem foi atribuída a instituição das modernas ciências sociais no Brasil? Mesmo sem a pretensão de adentrar a operação historiográfica complexa desses autores, algumas cartas endereçadas a Garcia podem guiar-nos nesse sentido. 


\section{Destinatário de um "bombardeio" de perguntas}

Prezado Sr. Rodolfo Garcia: Saudações

Escrevo para pedir-lhe um esclarecimento relativo à nossa história: Tratase do seguinte: Na devassa a que se procedeu em consequência dos acontecimentos de 21 de abril de 1821 na Praça do Comércio (publicada nos Documentos para a História da Independência - Biblioteca Nacional), figura uma testemunha, José Joaquim da Rocha, que era aliás um dos eleitores. Muito me interessava saber se este é o mesmo que o mais tarde Conselheiro José Joaquim da Rocha, que tamanho papel desempenhou na independência. (PRADO JÚNIOR 13 dez. 1942).

A relevância que Caio Prado Jr. deu para a pesquisa solicitada nessa carta datada de 13 de dezembro de 1942, ano em que publicou a obra Formação do Brasil Contemporâneo, parece também uma forma de valorizar a prática e empolgar aquele que foi incumbido dela. Na continuação da carta, o historiador paulista, cuja obra é associada à promoção da nacionalização do marxismo, fez questão de pontuar que a informação requerida ia além de um "pormenor curioso", característica geralmente atribuída pela historiografia moderna à perspectiva da pesquisa antiquária, considerada restrita ao passado e desvencilhada da história. Caso Rodolfo Garcia levantasse informações que confirmassem sua hipótese, elas trariam contribuições para a história da independência, acrescenta o autor, pois o depoimento dado pelo leitor Rocha ganharia novo significado vindo do Conselheiro Rocha.

Essas justificativas dadas por Caio Prado Jr. para sua "encomenda" nos remete a uma definição do ofício de Rodolfo Garcia. Não se tratava "simplesmente" de um erudito, pois as informações que tinha potencial para fornecer vinculavam-se a uma das temáticas fundamentais da historiografia brasileira. Em pouco tempo, Garcia tinha a resposta. Um dos Rocha era contador fiscal do Hospital Real Militar e prócer da independência e o outro homônimo cartógrafo e testemunha da Inconfidência Mineira.

Desfazer esse tipo de dúvida exigiam práticas metódicas, como o confronto do mesmo assunto em diversos documentos e a certificação de sua proveniência e sinceridade, além do conhecimento do período histórico e dos personagens em questão, que ajudariam a eliminar várias hipóteses até alcançar a resposta considerada verdadeira. Caio Prado Jr. também compartilhou de uma sistematização na escrita da história conforme a concepção moderna, mas, enquanto Garcia trabalhou para tornar-se um grande "leitor" de documentos e por essa via metódica preencher lacunas na história, ele desejou compor e compartilhar uma "leitura" do Brasil pautada no materialismo histórico. Nesse sentido, considerou a história como "um presente de nossos dias", por identificar sucessões dos mesmos ciclos no tempo e espaço, e privilegiou a economia em busca de interpretar a realidade formadora da nacionalidade brasileira. Os métodos para observá-la iam além do gabinete: "é muitas vezes preferível uma viagem pelas nossas diferentes regiões, à compulsa de documentos e textos" (PRADO JÚNIOR 1954, p. 30). 
A viagem como experiência que possibilita encontrar e conhecer foi uma questão que perpassou a historiografia brasileira desde o século XIX. Também em Gilberto Freyre o sentido da viagem ganha destaque. Entre suas idas e vindas pelo Brasil e pelo mundo, ele enviou de Lisboa a seguinte carta para Garcia:

Ilustre amigo e conterrâneo: Soube pelo meu querido amigo Manuel Bandeira da sua nomeação para Diretor do Museu Histórico. Ótima. Havia o Brasil de escrever sempre tão certo com a mão esquerda... Aqui estou desde os primeiros dias de novembro. Tenho estado sempre com o João Lúcio de Azevedo, que anda doente, mas sempre vivo de espírito. E na Biblioteca Nacional tomei assinatura. Estou agora de partida para os Estados Unidos, passando antes um mês na Espanha, da qual desejo conhecer aspectos do Sul, já tendo atravessando o Norte da outra vez que estive na Europa. Dos Estados Unidos, da Universidade de Stanford, Califórinia, recebi um convite para dar curso de história social do Brasil, na Faculdade de Ciências Sociais. Devo partir a 17 de março para New York. Ficaria muito agradecido se o ilustre amigo enviasse seus trabalhos de história, para aquela Universidade. O endereço é: Gilberto Freyre, Department of History, Stanford University, Cal., U.S.A. O mesmo pedido faço, por seu intermédio, ao Dr. Max Fleiuss e outros distintos investigadores [...] (FREYRE 18 fev. 1931).

Para demonstrar seu contentamento com a nomeação de Rodolfo Garcia como diretor do MHN, Freyre expressa também uma visão otimista de um Brasil que fazia escolhas certas, mesmo que por acaso. O otimismo, além de adjetivo, funcionou como crítica de pesquisadores da escravidão que discordaram do caráter amistoso com que Freyre concebia a relação entre senhores e escravos. O estilo ensaístico de sua produção, que possibilitava burlar a dicotomia entre poético e científico, também abriu caminhos para interpretações tidas como ousadas. Nesse estilo de história, as viagens de Freyre ganharam, com frequência, um estatuto de autoridade daquele que viu, legitimando sua perspectiva a respeito de questões norteadoras de sua produção, como a mestiçagem tratada em Casa-grande \& senzala a partir da relação entre raças e culturas.

Alguns escritos de Garcia já haviam viajado para Nova Iorque antes de Freyre, com Rüdiger Bilden. Esse jovem veio de Eschweiler, na Alemanha, para os Estados Unidos e iniciou o mestrado na Columbia University em 1920, onde estabeleceu contato com o colega Freyre e o professor Franz Boas. Antes de Freyre, Bilden já apontava para um equilíbrio social e fusão de elementos étnicos no Brasil. Suas pesquisas a respeito da "influência da escravidão no desenvolvimento do Brasil", tema pouco abordado até então, impulsionaram sua vinda ao país em 1925, onde permaneceu até abril de 1927. Em maio do mesmo ano, escreveu de Nova Iorque para Garcia. Além da saudade do Brasil, das conversas com Garcia e Max Fleiuss e das pesquisas no IHGB, Bilden inicia aquela carta escrita em inglês com um "bombardeio" de perguntas e pedidos:

Você me enviaria, por gentileza, o número da Revista $(84,1918)$, que contém o seu artigo "A Capitania de Pernambuco no Governo de José Cesar de Menezes", o qual eu estou ansioso para ler. Além disso, assim que o livro do Dr. Calógeras estiver disponível no Instituto, me envie uma cópia, preciso muito desse trabalho para a minha escrita. Mostrei 
seu Glossário de palavras indígenas em Claude d'Abbeville para Professor Franz Boas, Chefe do Departamento de Antropologia da Universidade de Columbia. Ele estava muito interessado nela e solicita através de mim para enviar-Ihe uma cópia, se isso é possível. (BILDEN, 25 mai. 1927).

O texto de Garcia que interessou a Franz Boas, reconhecido como fundador da moderna pesquisa etnográfica nos Estados Unidos, foi, na verdade, uma edição crítica e anotada feita da obra escrita em 1614 pelo frade francês Claude D'Abbeville a respeito dos tupis do Maranhão: Histoire de la mission des pères capucins en l'isle de Marignan et terres circonvoisines où est traicté des singularitez admirables \& des moeurs merveilleuses des indiens habitans de ce pais. Garcia selecionou palavras e frases da língua Tupi contidas no livro e formou um Glossário que acompanhou a primeira edição da obra publicada no Brasil, em 1922 (D'ABBEVILLE 1945). Mas, esse não foi o único esforço de Garcia para criar "inventário das palavras", como definiu o objetivo de seu Diccionario de brasileirismos (peculiaridades pernambucanas) (GARCIA 1913, p. 638). As pesquisas linguísticas que acompanharam todo seu percurso e merecem estudo específico filiaram-se a uma matriz que reconhecia os regionalismos como evolução e não deturpação da língua. Por esse viés, o vocabulário regional correspondente às peculiaridades pernambucanas era parte de um vocabulário brasileiro, os brasileirismos.

No início de 1931, quando Garcia recebeu o pedido de Freyre, ainda não havia escrito sua História Política e Administrativa do Brasil, mas, além do Glossário e do Diccionario de brasileirismos, que teve a primeira publicação em 1913, tinha textos avulsos na área de história, etnografia e pequenas biografias publicadas em revistas. Havia participado também na escrita coletiva do Dicionário Histórico, Geográfico e Etnográfico do Brasil com os capítulos "Etnografia Indígena" e "História das Explorações Científicas no Brasil", além da anotação de importantes obras do período colonial e publicações comentadas de conjuntos documentais. Não sabemos se Freyre utilizou alguns desses materiais no curso de história social do Brasil, mas, na obra publicada dois anos mais tarde, Casa-grande \& senzala, fez sete referências aos escritos de Garcia, três delas a respeito das notas aos Diálogos das Grandezas do Brasil. Nesses "monólogos" estabelecidos em uma espécie de "segundo plano" do texto, as notas de rodapé de Freyre a respeito das anotações de Garcia tinham a função de legitimar e complementar a narrativa. Se no texto Freyre tratava do aumento da produção do açúcar em Pernambuco no início do século XVII, por exemplo, Garcia informava a quantidade de engenhos na nota (FREYRE 2003, p. 558). A respeito das superstições e medos de animais monstruosos entre os chamados "selvagens", o comentário de Garcia traz exemplos contando do agouro atribuído ao canto da peitica, um tipo de pássaro que, segundo ele, permanecia temido por seus contemporâneos nos Estados do Norte (FREYRE 2003, p. 250).

Mas é a prática de esclarecer a quais pessoas correspondiam os nomes e apelidos mencionados em documentos que parece estar entre as atividades que os chamados intérpretes do Brasil da década de 1930 mais delegaram à Garcia. 
O nome de Garcia foi citado por Freyre para confirmar a hipótese de que Mangue La Bote correspondia ao conhecido capitão-mor Baltasar de Aragão, falecido no mar (FREYRE 2003, p. 264) - investigação semelhante àquela pedida por Caio Prado Jr.em relação a José Joaquim da Rocha. É possível dizer, assim, que constituir um estilo de escrita diferente das monografias predominantes até então não significava ignorar a necessidade de investigar e dar a conhecer a credibilidade dos dados, mas talvez ampliar as modalidades dessa verificação. Delegava-se a confirmação e retificação de informações documentais aos que tinham maior domínio da prática do método crítico enquanto buscava-se interpretar a realidade, que já não era suficientemente inteligível pelas fontes escritas e oficiais do passado, pois reclamava por uma investigação mais atenta ao presente, em diálogo com os métodos das Ciências Sociais.

Também para Rüdiger Bilden, Garcia era o modelo de historiador com tirocínio metodológico e, no entanto, pouco reconhecido por suas atividades, o que demonstrava o atraso cultural do Brasil e sua incapacidade de valorizar as realizações científicas dos próprios brasileiros. Segundo ele, Garcia era uma "figura um tanto patética, vivendo em relativa pobreza e num meio superficial, não tendo oportunidade de viajar ou debater com seus iguais" (BILDEN apud BURKE 2012, p. 169). Mas, talvez fosse nas conversas que tinha em seu gabinete da BN que Garcia sentia-se à vontade para "debater com seus iguais". Costumava viajar, sim, para pesquisar o passado nos documentos, não sem antes certificarse que o "trajeto" era seguro. Essas viagens de gabinete, próprias da história

126 erudita, eram insuficientes, porém, para ensaístas que buscavam apreender a experiência histórica do povo como Caio Prado Jr. e Gilberto Freyre.

\section{Considerações finais}

As várias possibilidades que o período ofereceu para inventariar o Brasil e escrever sua história guardavam um compromisso comum com a especialização dessa área do saber e com a promoção do status de uma profissão, seja por meio dos resultados de pesquisa que testavam os limites das regras estabelecidas até então ou mesmo pelos esforços, como os de Rodolfo Garcia, para reafirmálas. Investigando os modos com que seus pares o narraram e as demandas que recebeu no exercício de historiador, pudemos vislumbrar algumas das características que correspondiam ao perfil do erudito e do intelectual naquele período e compreender as motivações dos que assim o consideraram. Tais esboços de Garcia que identificamos nas correspondências analisadas conferiram a ele um ar assertivo a respeito das "provas" do passado. O amplo conhecimento de história do Brasil, aliado a um saber arquivístico e bibliotecário, possibilitou que Garcia sanasse as mais diversas dúvidas dos que recorriam a ele, frequentemente em busca de informações pontuais.

Assim, o ofício polivalente desempenhado por Garcia, ao lado de outros tantos historiadores autodidatas como Capistrano de Abreu e Afonso d'Escragnolle Taunay, desempenhou um importante papel na especialização dos saberes, promovida de modo crescente em uma sociedade que passa a recorrer constantemente à palavra "moderno" para significar seu presente e 
suas aspirações. Com isso, o Garcia erudito foi denominado por representantes do poder político como intelectual, designação que dava uma roupagem nova aos que representavam a ilustração brasileira e se dispunham a colaborar com a política cultural da Era Vargas.

Enfim, os esboços de Garcia localizados nas cartas nos apontam um período de coexistências. Promover a especialização e ser denominado intelectual não significou necessariamente desapegar-se de uma concepção do saber abrangente, do mesmo modo que figurar entre os eruditos não implicou em uma postura reclusa em relação à modernização dos estudos históricos.

\section{Referências bibliográficas}

ALBUQUERQUE JúNIOR, Durval. Muniz de. Da história detalhe à história problema: o erudito e o intelectual na elaboração e no ensino do saber histórico. Lócus - Revista de história, v. 10, n. 2, p. 53-72, 2004.

De amadores a desapaixonados: eruditos e intelectuais como distintas figuras de sujeito do conhecimento no Ocidente. Trajetos. Revista de História da Universidade Federal do Ceará, v. 3. n. 6, p. 3-66, 2005.

ANHEZINI, Karina. Na entrecena da construção da história do Brasil (18781934). In: MEDEIROS, Bruno Franco et al. (Org.) Teoria e Historiografia: Debates Contemporâneos. Jundiaí: Paco, 2015, p. 233-246. v. 1.

BILDEN, Rüdiger. Carta a Rodolfo Garcia. Nova York, 25 mai. 1927. Coleção Rodolfo Garcia. Biblioteca Nacional do Brasil, caixa sem identificação.

PALLARES-BURKE, Maria.Lúcia.Garcia. O triunfo do fracasso: Rüdiger Bilden, o amigo esquecido de Gilberto Freyre. São Paulo: Ed. Unesp, 2012.

CAMARGO, Angélica Ricci. Em busca de uma política para o desenvolvimento do teatro brasileiro: as experiências da Comissão e do Serviço Nacional de Teatro (1936-1945). Dissertação (Mestrado em História Social) Universidade Federal do Rio de Janeiro, Rio de Janeiro, 2011.

CAPANEMA, Gustavo. Carta a Rodolfo Garcia. Rio de Janeiro, 7 jun. 1943. Coleção Rodolfo Garcia. Biblioteca Nacional do Brasil, caixa sem identificação.

CERTEAU, Michel de. A escrita da história. Rio de Janeiro: Forense Universitária, 1982.

COSTA, Antonio.da Silva.Ferreira. Carta a Rodolfo Garcia. Pelotas, 6 abr. 1945. Coleção Rodolfo Garcia. Biblioteca Nacional do Brasil, caixa sem identificação.

D'ABBEVILLE, Claude. História da missão dos padres capuchinhos na Ilha do Maranhão e terras circunvizinhas. Tradução de Sérgio Milliet, introdução e notas de Rodolfo Garcia. São Paulo: Livraria Martins, 1945.

FREYRE, Gilberto. Carta a Rodolfo Garcia. Lisboa, 18 fev. 1931. Coleção Rodolfo Garcia. Biblioteca Nacional do Brasil, caixa sem identificação. 
Casa-grande \& senzala: formação da família brasileira sob o regime de economia patriarcal. São Paulo: Global, 2003.

FURET, François. O nascimento da história. In:

A oficina da história. Trad. Adriano Duarte Rodrigues. Lisboa: Gradiva, s.d, p. 109-135.

GARCIA, Rodolfo Augusto de Amorim. Carta a Capistrano de Abreu. sl, sd. In: RODRIGUES, J. H. (Org.). Correspondência de Capistrano de Abreu. Rio de Janeiro: Civilização Brasileira; Brasília: INL, 1977, p. 103-104. v. 3.

. Diccionario de brasileirismos (peculiaridades pernambucanas). Revista do IHGB, t. LXXVI, parte I, p. 638, 1913.

GÓES, Eurico de. Carta a Rodolfo Garcia. São Paulo, 4 nov. 1937. Coleção Rodolfo Garcia. Biblioteca Nacional do Brasil, caixa sem identificação.

GOMES, Angela de.Castro. História e historiadores: a política cultural do Estado Novo. Rio de Janeiro: Ed. FGV, 1996.

GONTIJO, Rebeca. O velho vaqueano: Capistrano de Abreu (1853-1927): memória, historiografia e escrita de si. Rio de Janeiro: 7 Letras, 2013.

GRAFTON, Antony. As origens trágicas da erudição: pequeno tratado sobre a nota de rodapé. Campinas: Papirus, 1998.

GUIMARÃES, Manoel. Luiz. Salgado. Reinventado a tradição: sobre antiquariado e escrita da história. Humanas, v. 23, n. 1/2, p. 111-143, 2000.

128 HARTOG, François. Memória de Ulisses: narrativas sobre a fronteira na Grécia Antiga. Belo Horizonte: Ed. UFMG, 2004.

. O espelho de Heródoto: ensaio sobre a representação do outro. Tradução de Jacyntho Lins Brandão. Belo Horizonte: Ed. UFMG, 1999.

MICELI, Sergio. Intelectuais à brasileira. São Paulo: Companhia das Letras, 2001.

MOMIGLIANO, Arnaldo. O surgimento da pesquisa antiquária. In: As raízes clássicas da historiografia moderna. Trad. Maria Beatriz Borba Florenzano. Bauru: EDUSC, 2004.

NICOLAZZI, Fernando. Um estilo de história: a viagem, a memória, o ensaio. Sobre Casa-grande \& senzala e a representação do passado. Tese (Doutorado em História) - Universidade Federal do Rio Grande do Sul, Porto Alegre, 2008.

PAUL, Herman. Historicismo fraco: sobre hierarquia de virtudes e de metas intelectuais. História da historiografia, n. 21, p. 25-42, 2016.

PRADO JÚNIOR, Caio. Carta a Rodolfo Garcia. São Paulo, 13 dez. 1942. In: DAMASCENO, D. (Org.). Cartas a Rodolfo Garcia. Rio de Janeiro: Biblioteca Nacional, 1970, p. 145-146.

Diretrizes para uma política econômica brasileira. São Paulo: Brasiliense, 1954. 
SCHWARTZMAN, Simon; BOMENY, Helena. Maria. Bousquet; COSTA, Vanda. Maria.Ribeiro. Tempos de Capanema. 2. ed. São Paulo: Paz e Terra; Rio de Janeiro: Ed. FGV, 2001.

SCHWARTZ, Stuart. Gilberto Freyre e a História colonial: uma visão otimista do Brasil. In: Joaquim Falcão e Rosa Maria Barboza Araújo (Org.). O imperador das idéias: Gilberto Freyre em questão. Rio de Janeiro: Topbooks, 2000, p. 1-107.

SEVCENKO, Nicolau. A capital irradiante: técnica, ritmo e ritos do Rio. In: NOVAIS, Fernando (Coord.); SEVCENKO, N. (Org.). História da Vida Privada no Brasil. São Paulo: Companhia das Letras, 1998, p. 513-619. v. 3.

TAUNAY, Afonso.de Escragnolle. Carta a Rodolfo Garcia. São Paulo 23 abr. 1926. In: DAMASCENO, D. (Org.). Cartas a Rodolfo Garcia. Rio de Janeiro: Biblioteca Nacional, 1970, p. 59.

VARELA, Alfredo. Carta a Rodolfo Garcia. Rio de Janeiro, 8 out. 1941. In: DAMASCENO, D. (Org.). Cartas a Rodolfo Garcia. Rio de Janeiro: Biblioteca Nacional, 1970, p. 139. . Carta a Rodolfo Garcia. Rio de Janeiro, 28 fev. 1942. Coleção Rodolfo Garcia. Biblioteca Nacional do Brasil, caixa sem identificação. 